\title{
LA LETRA CON SANGRE ENTRA. VIOLENCIA CONTRA LA MUJER EN DOS NARRADORAS CUBANAS: MARILYN BOBES Y LAIDI FERNÁNDEZ DE JUAN'
}

\author{
THE LETTER WITH BLO0D ENTERS. VIOLENCE AGAINST \\ WOMEN IN WORKS BY TWO CUBAN FEMALE WRITERS: \\ MARILYN BOBES AND LAIDI FERNÁNDEZ DE JUAN
}

\author{
María del Mar López-Cabrales²
}

\begin{abstract}
RESUMEN: A través del análisis de los cuentos "La infamia" de Marilyn Bobes y "Bumerang" de Laidi Fernández de Juan se quiere demostrar que, a su manera, las narradoras de estas historias intentan resistirse a lo que la sociedad patriarcal espera de ellas. En estos textos se demuestra que la violencia hacia la mujer se presenta como un fenómeno social que posee lo que denominamos "efecto luz de gas" porque lentamente va destruyendo a la mujer. Esta violencia posee diferentes aristas y manifestaciones que, a veces, el sistema patriarcal desestima, consiguiendo que el feminicidio sea una triste realidad cotidiana y que los perpetradores sigan libres, porque muchos de estos casos se inscriben como unas riñas domésticas (o "disputa privada" (18), como se expresa en "La infamia") no castigadas por el Código Penal. En este artículo se estudia este tema a través del análisis de los textos de estas dos escritoras cubanas contemporáneas.
\end{abstract}

Palabras-claves: Violencia contra la mujer, Cuba, Marilyn Bobes, Laidi Fernandez de Jua, Efecto luz de gas, Nepantla

ABSTRACT: Through the analysis of the stories "La infamia" by Marilyn Bobes and "Bumerang" by Laidi Fernández de Juan, this article argues that the narrators in these two short stories are trying to resist patriarchal expectations from society. These texts show that violence against women is a social phenomenon that has a "gas light effect" that slowly destroys women. This violence has different angles and manifestations that, sometimes, the patriarchal system dismisses. Feminicide a sad daily reality and perpetrators often remain free because many of these cases are registered as domestic violence cases (or "private disputes" (18), as expressed by the narrator lluminada in the short story "La infamia") and not punished by the Criminal Code. In this article, this topic is studied through the analysis of the texts of these two contemporary Cuban writers.

Keywords: Violence against women, Cuba, Marilyn Bobes, Laidi Fernández de Jua, gas light effect, Nepantla.

\footnotetext{
${ }^{1}$ Artigo recebido em 14 de agosto de 2019 e aceito para publicação em 20 de novembro de 2019

${ }^{2}$ Colorado State University 
El tema de la violencia de género está empezando a ocupar un lugar central en las letras hispanas. Gracias a una larga historia en común de opresión femenina y a la repercusión mediática de movimientos como \#Time's Up y \#Ni una menos, \#Yo también, las escritoras por fin comparten sus historias sin pelos en la lengua. En Cuba este grito de género lleva tiempo escuchándose. Solo tenemos que atender a textos publicados por escritoras como Mirta Yáñez, Marylin Boves, Ena Lucía Portela o Wendy Guerra, por citar a algunas de las más conocidas. En esta ponencia se analizan y contrastan dos textos recientemente publicados en la Isla en la antología Sombras nada más. 36 escritoras cubanas contra la violencia hacia la mujer y compilada por Laidi Fernández de Juan (La Habana: Ediciones Unión 2015). Contrastar estas historias y presentar conclusiones, dada la dificultad de acceder a los textos publicados en Cuba, y atender a las demandas de las escritoras que residen y publican allí, es una labor necesaria. De esta manera, y desde la perspectiva de los estudios de género, queremos analizar cómo estas escritoras reflexionan en sus textos sobre la violencia contra la mujer y proponen la necesidad de una transformación radical desde la.

Propongo la necesidad de un estudio que tenga en cuenta la conexión entre distintos discursos artísticos que traten este tema (narrativos, plásticos, cinematográficos y musicales), ya que sus creadoras, partiendo de un conocimiento profundo y con gran respeto hacia las mujeres abusadas, están haciendo propuestas de denuncia contra la violencia hacia la mujer, sin caer en consabidos paternalismos.

El mensaje de empoderamiento de estos textos se relaciona con el movimiento actual de las mujeres y aporta un rayo de esperanza en un momento como el actual, en el que existe un claro retroceso en materia de acercamiento a las minorías, se impone una mentalidad que las rechaza y excluye, además de que avanza peligrosamente un discurso que inocula un mensaje claramente machista y de cosificación del cuerpo femenino. Creadoras cubanas como las que vamos a analizar hoy: Marilyn Bobes en su cuento "La infamia" y Laidi Fernández Juan en "Bumerang", tratan de agitar las conciencias y contraatacan lanzado un mensaje de empoderamiento de la mujer y en contra de la violencia machista.

En el mundo del cine, por ejemplo, Barbara Zecchi acuñó en 2014 el término "ginocine" y lo aplicó a todo cine que se relacione con la representación de la mujer y la posición de ésta en la sociedad. “El ginocine 
no es necesariamente feminista: pero su lectura sí lo es" (Everly 183). Este término es un neologismo y le sirvió a Zecchi de propuesta para corregir las limitaciones de los términos "cine feminista", "cine femenino" y "cine de mujeres". El concepto se basa en los planteamientos de los años 70 de la teoría literaria feminista y la ginocrítica, término acuñado por Elaine Showalter en su texto A Literature on Their's Own que consiguió rescatar unos textos escritos por mujeres que la crítica de resistencia protagonizada por Virgina Woolf y su libro $A$ Room of One's Own aún no conocía.

La mirada de la mujer como crítica o productora de imágenes transgresoras en las artes cabe dentro de lo que bell Hooks denominó en 1992 "oppositional Gaze" que surge en contra de la mirada masculina blanca y que se posiciona dentro del campo de la interseccionalidad, donde no solo el género, sino también la raza, el poder y la clase son determinantes en la producción de cualquier discurso cultural. La tercera ola del feminismo (Rebecca Walker, Diane Elam) se plantea como un movimiento sociopolítico que va más allá de la lucha de la mujer porque se basa en una lucha por los derechos de los sectores más marginados de la sociedad. Por ello, los textos de Laidi Fernandez de Juan y Marilyn Bobes, las distintas producciones de cine sobre la mujer y la violencia contra ella, así como creaciones musicales y artísticas que denuncian la violencia hacia la mujer y proponen el poder femenino como fuerza opuesta a la globalización y el capitalismo.

La resistencia de la mujer ha sido visible a lo largo de la historia, desde la caza y demonización de las brujas de los siglos XVI y XVII, la división sexual del trabajo y la expropiación de la tierra que se hizo a los campesinos a comienzos del desarrollo del capitalismo y la reclusión de la mujer al hogar y la reducción de la misma a un ser cuyo máximo objetivo en la vida en su función reproductiva (Gómez 17), hasta los días de hoy en los que las mujeres a pesar de realizar un $66 \%$ del trabajo mundial, producir el $50 \%$ de los alimentos, ganan solo el $10 \%$ de los ingresos y son tan solo dueñas de un $1 \%$ de la propiedad (Gómez 18). La responsabilidad de la crítca es abrir un diálogo con las representaciones que se hacen en los medios de la violencia contra la mujer, ampliar perspectivas y hacer preguntas arriesgadas que nos ayuden a reflexionar sobre la realidad que nos rodea para poder mostrar nuevas subjetividades más plurales.

Los cuentos que analizaremos a continuación presentan una mirada transversal que intenta subvertir los estereotipos de género y se 
resisten a la violencia contra las mujeres a través de personajes como lluminada Peña en "La infamia" y, la narradora-escritora innominada del cuento "Bomerang" que se oponen a lo que sus parejas, familiares y la sociedad, en general, esperan de ellas. Estos sujetos narrativos son inconformistas y desean romper el círculo que las oprime porque, pese a sentirse arraigadas y parte de su cultura cubana, reflexionan, escriben y disienten, ya que ellas se perciben como disitinas. Esta sensación liminal de vivir eternamente en una especie de puente "in between" (en la frontera) se asemeja a ese nepantla, (náhuatl) o tierra entre medio del que tanto hablara Gloria Anzaldúa (1987):

Los puentes son umbrales a otras realidades, símbolos arquetípicos, primitivos de la conciencia cambiante. Son pasajes, conductos y conectores que connotan la transición, el cruce de fronteras y las perspectivas cambiantes. Los puentes abarcan espacios que comunican entre mundos, espacios que llamo nepantla, una palabra náhuatl que significa tierra entre medio. Las transformaciones ocurren en este espacio intermedio, un espacio inestable, impredecible, precario, siempre en transición, que carece de límites claros. Nepantla es tierra desconocida, y vivir en esta zona comunicante significa estar en un estado constante de desplazamiento, una sensación incómoda, incluso alarmante. La mayoría de nosotros moramos en nepantla la mayor parte del tiempo y comienza a ser una especie de "hogar". Aunque este estado nos une a otras ideas, personas y mundos, nos sentimos amenazados por estas nuevas conexiones y el cambio que engendran (Traducción de (Un)natural bridges from This Bridge We Call Home: Radical Visions for Transformation. Editores Gloria Anzaldúa, AnaLouise Keating. Editorial Routledge, 2013)

A través del análisis de estos textos quisiera demostrar que la violencia hacia la mujer se presenta como un fenómeno social con diferentes aristas y manifestaciones, que a veces el sistema patriarcal desestima, consiguiendo que el feminicidio sea una triste realidad cotidiana y que los perpetradores sigan libres porque muchos de estos casos se inscriben como unas riñas domésticas (o "disputa privada" (18), como se expresa en "La infamia") no castigadas por el Código Penal.

Se estima que un 35 por ciento de las mujeres en todo el mundo ha experimentado violencia física o sexual de una persona que no es su pareja 
y cerca del 70 por ciento ha sido abusada por su propia pareja ("Facts and figures. Ending Violence Against Women", UN Women). Estos números son altos, pero hay un tipo de abuso que es parte de la violencia no tangible, el abuso psicológico, mental y emocional que consiste en algún comportamiento no físico con intento de "controlar, someter, castigar, o aislar alguna persona a través del uso de la humillación o el miedo" (Karakurt). Este tema es complicado porque la sociedad, si no hay evidentes efectos físicos como consecuencia del abuso, no tiende a tomar la violencia psicológica en serio. La violencia psicológica incluye cualquier acción o palabra que dañe las emociones y la autoestima de la mujer (Violencia contra la mujer) y “puede manifestarse como acoso, restricción, humillación, manipulación o aislamiento, produciendo daños emocionales y perjudicando nuestro desarrollo personal hasta problemas emocionales y psicológicos muy graves que han llevado a muchas mujeres al suicidio" ("Tipos de violencia contra las mujeres"). Es la forma de violencia más común con un 41 por ciento de mujeres que lo sufren (Sfranoff). Para ver ejemplos y opiniones sobre este tema, se puede ir a \#QuizasNoTePegue de la escritora dominicanaestadounidense Zahira Kelly que propone 5 señales. (“Cinco señales de que eres víctima de abuso emocional. BBC News Mundo". BBC News, BBC 21 May 2016).

La tragedia de la violencia contra la mujer hace que esta sienta miedo en una relación íntima a causa de amenazas "contra su vida, su libertad, su dignidad, su integridad física, psicológica o sexual, su situación económica o su seguridad" ("Violencia contra la mujer"). En estos cuentos vemos los diferentes tipos de violencia contra la mujer para demostrar que la violencia física es la única castigada por el Código Penal pero no la única existente. El problema de los roles de género y de cómo la sociedad espera algo de las mujeres que no todas quieren ser se observa en "El cotorreo" de la escritora afrocubana Georgina Herrera: "Sabemos que tenemos derechos iguales a nuestra pareja... pero si seguimos acompañadas, somos las que llegamos primero a la casa, mientras el hombre, también por tradición, llega a la hora que le parece, y su explicación, aunque cierta, es una ofensa, porque "unos amigos me invitaron a un trago, vieja, y tú sabes cómo es eso"” (103). La tradición sobre los roles de género hace que se perpetúe y se normalice el abuso y el maltrato a la mujer y la libertad que esta tiene en el seno del hogar como cuidadora del mismo (ama de casa). Hay varias perspectivas sobre el 
abuso y la violencia doméstica. La teoría feminista defiende que el sistema patriarcal ha formado una sociedad en la que existe una aceptación total de la autoridad del hombre sobre el control absoluto de las mujeres (RakovecFelser). De ahí que estos tipos de abusos sean presentados como algo normal y no digno de tener en cuenta.

En el cuento "Bumerang" se observa estos tipos de violencia contra la mujer. La voz narrativa expresa el daño psicológico cuando su novio la está poniendo en prueba y bucean por una cueva: "Pasé mucho tiempo buscándote en el agua. Tanto, que casi se acaba el oxígeno de mi tanque, hasta que, desfallecida, encontré la salida de la cueva y fui hasta la claridad de arriba. Tú estabas en la orilla sin el traje de buceo, y me esperabas sonriendo" (47). Aquí vemos un claro ejemplo del sentimiento de pánico, miedo y aislamiento, hasta humillación y manipulación que sufre el sujeto femenino en este cuento cuya pareja dijo haberle puesto a prueba no solo su resistencia en el agua, sino también su lealtad hacia él. En este cuento, la voz narrativa describe lo negativo de la protagonista innominada y el hecho de que ésta se sienta más culpable de las reacciones violentas de su pareja: "Te agradezco el recurso y el método que empleaste para demostrar mis imperfecciones" (19).

En "La infamia", aunque la violencia física es la que impera, también se observa la psicológica. lluminada se siente culpable del propio abuso físico que sufre por parte de su pareja: "El Bebo no tenía excusa del alcohol y la muchacha se preguntaba si no sería ella misma, su mera existencia, la que desataba la agresividad de su enamorado" (19). Igualmente, ella se culpa de la paliza que su pareja le pega después de la noche de baile en El Tropical. Después de la "andanada de galletazos" (20), fue ella la que le pidió disculpas, porque su comportamiento fue inapropiado al bailar en La Tropical con un conocido, Rufo.

No fue su novio quien la llamara arrepentido. lluminada en persona lo había ido a buscar hasta el parque Maceo para pedirle perdón. Reconocía que su actitud con Rufo no era la de una muchacha decente [...] pero le juraba a El Bebo que eso no ocurriría otra vez, que cuando fueran a La Tropical no se despegaría de su lado ni bailaría con nadie más [porque él era] el amor de su vida, el único hombre del que había estado verdaderamente enamorada (20). 
El Bebo la manipula hasta el punto de que ella se siente inferior a él y culpable de algo, aunque fue el perpetrador quien realizó la injuria, además de que fue él quien la dejó sola en la pista para irse a beber cervezas con los amigos. La cultura machista del sistema patriarcal sitúa a la mujer en un espacio inferior con respecto al hombre solo por el hecho de que esta sea mujer. En "La infamia” Iluminada se encuentra en una relación tóxica porque en este tipo de relaciones, el abuso comienza con reproches, después con insultos y finalmente con violencia física. "La muchacha se preguntaba si no sería ella misma, su mera existencia, la que desataba la agresividad de su enamorado" (19). Esta violencia es justificada por ella, por su madre, por los vecinos, la sociedad entera ve esta violencia como una riña doméstica sin importancia.

En "Bumerang" se puede leer: "Me hiciste saber en detalle cuán lejos estaba yo de haberme acercado a dicha superioridad, aunque a tu lado, si prestaba la debida atención, quizás lo lograra con el paso del tiempo" (49). La pareja de la narradora innominada ejerce un control absoluto sobre ella y posee la clave para que ésta consiga acercarse a la superioridad del hombre que constantemente le está dando lecciones. La voz narrativa ve a su novio como una especie de salvador y maestro de vida, ya que su pareja llama a estos maltratos "lecciones de vida", uno de los ejemplos más claros es cuando le tira un plato de espaguetis calientes sobre la cabeza porque ella no los había cocinado a su gusto y ella lo toma como un aprendizaje: "No sabes cuánto te lo agradezco... no te conté que me ardía el cráneo, porque el descubrimiento de lo correcto en cuanto a lo que me habías enseñado era superior a esa molestia, que considerarías banal" (48). Le había enseñado que no había que mostrar los sentimientos ni las molestias porque estos nos hacían débiles. Todas estas lecciones de vida no solo son abusos físicos, sino también psicológicos, porque después de dañarle, le trata con gentileza y le convence de que todo lo hace por su bien. Esta manipulación tiene un nombre: "Luz de gas" y es un maltrato difícil de delatar:

El abuso luz de gas es una forma de violencia muy perversa porque es continua y se consigue mediante el ejercicio de un acoso constante pero sutil e indirecto, repetitivo, que va generando duda y confusión en la mujer que lo sufre, hasta el punto en que se llega a sentir culpable de las conductas de violencia emitidas 
por el maltratador y a dudar de todo lo que ocurre a su alrededor (Carretero)

Este tipo de abuso es muy peligroso porque desarma a la mujer para que no reconozca el mal que le están haciendo, el sufrimiento. Después de experimentar este tipo de violencia luz de gas, la mujer puede recibir una paliza y pensar que ella es la culpable. Es muy difícil delatar un abuso de este tipo catalogado psicológico porque no hay evidencia física. En la cultura machista del sistema patriarcal muchas veces la manipulación no es reconocida como abuso, pero es una herramienta muy poderosa que muchos usan para desarmar a sus parejas y controlarlas. Cuando la mujer ya no cree que puede pensar por sí misma, cuando ya no se ve a sí misma como un ser humano independiente y propio, nos damos cuenta de lo peligroso que es la manipulación. Aunque la voz narrativa de la "La infamia" no nos deja saber todo lo que lluminada piensa, su escritura nos permite que entendamos los pensamientos de una mujer que se siente atrapada o desesperada, y por eso sus acciones al final del cuento son igualmente más entendibles, aunque extremas, porque nos ayudan a entender mejor su frustración, confusión, dolor y miedo. lluminada experimenta unos sentimientos que la mayoría de las mujeres en relaciones abusivas sienten. Muchas mujeres como lluminada, en una cultura que no aborda estos problemas directamente, que en cierta manera hasta los justifica, y que no tiende puentes de ayuda a las víctimas, serán capaces de tolerar el abuso con la esperanza de que sea algo temporal, por amor, perdonarán, aunque al final tengan que huir, colapsar o convertirse en una de tantas víctimas del feminicidio.

Como vemos, los distintos tipos de violencia están conectados. La violencia física suele venir acompañada de la psicológica. El en caso de "La infamia", Iluminada se responsabiliza constantemente de los abusos y hasta los justifica. Además de la física, simbólica y psicológica, hay muchos otros tipos de violencia como la económica, institucional, laboral y sexual que se manifiestan en los distintos casos de violencia y sufrimiento de la mujer. Es nuestra labor como feministas y académicas, utilizar estos tipos de plataformas artísticas en nuestras clases y en nuestras investigaciones y publicaciones para crear conciencia de los abusos e intentar que no se repitan 


\section{Referencias}

Cinco señales de que eres víctima de abuso emocional. BBC News Mundo. BBC News, BBC 21 May 2016

Facts and figures. Ending Violence Against Women, UN Women, UN Women. Nov. 2018. https://www.unwomen.org/en/what-we-do/ending-violenceagainst-women/facts-and-figures

Tipos de violencia contra las mujeres: Violencia de género. Ayuda en Acción, Fundación de Ayuda en Acción, 7 May 2018. https://ayudaenaccion.org/ong/blog/mujer/tipos-violencia-mujeres/

Violencia contra la mujer. Ley 26.485. Derecho fácil. Ministerio de Justicia y Derechos Humanos. Presidencia de La Nación. Argentina. http://www.derechofacil.gob.ar/leysimple/violencia-contra-la-mujer/

ANZALDÚA, G. This Bridge We Call Home: Radical Visions for Transformation. Editores Gloria Anzaldúa, AnaLouise Keating. Londres: Editorial Routledge, 2013.

BISWAS, A. La tercera ola feminista: cuando la diversidad, las particularidades y las diferencias son lo que cuenta. Revista Casa del Tiempo, Vol. 06, Núm. 68, septiembre 2004, pp. 65-70.

BOBES, M. La infamia en Fernández de Juan, Laidi (selección). (2015). Sombras nada más. 36 escritoras cubanas contra la violencia hacia la mujer. La Habana: Ediciones Unión.

BROOKS, A. (2007). Feminist Standpoint Epistemology: Building Knowledge and Empowerment through Women's Lived Experience. Feminist Research Practice: A Primer, pp. 53-82.

BURGESS-PROCTOR, A. (2006). Intersections of Race, Class, Gender, and Crime: Future Directions for Feminist Criminology. Feminist Criminology, 1(1), 27-47.

CARRETERO, N. (2017, nov. 22) luz de gas, el maltrato machista que nadie parece ver. El país. https://elpais.com/politica/2017/09/15/actualidad/1505472042_655999.ht $\mathrm{ml}$

CRENSHAW, K. W. (2014). The Structural and Political Dimensions of Intersectional Oppression. Intersectionality: A Foundations and Frontiers Reader, 17-22. 
EVERLY, K. Acercamientos feministas al cine español y latinoamericano; La mujer como producto y productora de imágenes. Hispanófila, Volumen 177, junio 2016, pp. 179-193.

FERNÁNDEZ DE JUAN, L. (selección). (2015) Sombras nada más. 36 escritoras cubanas contra la violencia hacia la mujer. La Habana: Ediciones Unión.

FERNÁNDEZ DE JUAN, L. Bumerang en Fernández de Juan, Laidi (selección). (2015). Sombras nada más. 36 escritoras cubanas contra la violencia hacia la mujer. La Habana: Ediciones Unión.

GÓMEZ, LEILA, KAREN GENSCHOW Y KATARZYNA MOSZCZYNSKA-DURST. Prefacio al número especial: Capitalismo, Globalización y violencia de género Letras Femeninas (2018) Vol. 43,2, pp. 13-15.

HILL-COLLINS, P. (2000). Black Feminist Thought: Knowledge, Consciousness, and the Politics of Empowerment. (2nd ed.). New York: Routledge.

HOOKS, B. The Oppositional Gaze. Black Female Spectators. Black Looks: Race and Representation. Boston South End Press, 1992. 115-31.

HURTADO, A. (2003). Voicing Chicana Feminisms: Young Women Speak Out on Sexuality and Identity. New York: New York University Press.

ISASI-DÍAZ, A. M. (1996). Mujerista Theology: A Theology for the Twenty-First Century. New York: Orbis Books.

KARAKURT, G. y K. E. S. Emotional Abuse in Intimate Relationships: The Role of Gender and Age. Violencia and Vitctimus, U. S, National library of Medicine, 2013.

KASTURIRANGAN, A., KRISHNAN, S., \& RIGER, S. (2004). The Impact of Culture and Minority Status on Women's Experience of Domestic Violence. Trauma, Violence Abuse, 5(4), 318-332.

Letras Femeninas (2018). Capitalismo, Globalización y violencia de género Vol. 43, 2.

RAKOVEE-FELSER, Z. Domestic Violence and Abuse in Intimate Relationship from Public Health Perspective. Health Psychology Research, PAGEPress Publications, Pavia, Italy, 22 Oct. 2014.

SAFRANOFF, A. Violencia psicológica hacia la mujer ¿Cuáles son los factores que aumentan el riesgo de que exista esta forma de maltrato en la pareja?. Salud colectiva, vol. 13, p. 611-632. http://digital.cic.gba.gob.ar/handle/11746/6904, Doi: $10.18294 /$ sc. 2017.1145 
SNYDER, R. C. What Is Third Wave Feminism? A New Directions Essay. Signs, Vol. 34, Núm. 1, Autumn 2008, pp. 175-96.

SNYDER-HALL, R. C. Third-Wave Feminism and the Defense of 'Choice'. Perspectives on Politics, Vol. 8, Núm. 1, March 2010, pp. 255-61.

VALLE FERRER, D. (2011). Espacios de libertad: mujeres, violencia doméstica y resistencia. Buenos Aires: Espacio Editorial.

ZECCHI, B. Desenfocadas. Cineastas españolas y discursos de género y La pantalla sexuada. Madrid: Icaria, 2014. 